\title{
Impact of recreational harvesting on assemblages in artificial rocky habitats
}

\author{
Laura Airoldi $^{1,2, *}$, Francesca Bacchiocchi ${ }^{2}$, Claudia Cagliola ${ }^{2}$, Fabio Bulleri ${ }^{1,2}$, \\ Marco Abbiati ${ }^{2}$ \\ ${ }^{1}$ Dipartimento di Biologia Evoluzionistica Sperimentale, Università di Bologna, Via Selmi 3, 40126 Bologna, Italy \\ ${ }^{2}$ Centro Interdipartimentale di Ricerca per le Scienze Ambientali in Ravenna, Università di Bologna, Via S. Alberto 163, \\ 48100 Ravenna, Italy
}

\begin{abstract}
Man-made structures have become ubiquitous features of coastal landscapes. These artificial habitats are popular recreation sites. Patterns and effects of recreational activities were investigated from 1999 to 2004 on coastal structures along 40 km of shoreline in the Emilia Romagna region (North Adriatic Sea, Italy). Four studies estimated the magnitude and frequency of exploitation by people, and established how human exploitation varied in space and time. A manipulative experiment involving the removal of mussels, mimicking the impact of human harvesting, was carried out to identify the effects of extensive mussel exploitation. Recreational exploitation was a major recurrent disturbance. Hundreds of people visited defence structures for recreational fishing and to harvest a variety of invertebrates to be used primarily as food. Human exploitation was most intense during the spring and summer but relatively unpredictable at scales of days and hours. Exploitation was homogeneous among different locations, despite marked differences in the accessibility of the structures. Visitors to the structures were mainly local people. Harvesting of mussels was particularly disruptive for the assemblages, leading to depletion of mussel beds, opening of unoccupied space, patchiness in the assemblages, and favouring the development of macroalgae. The main types of macroalgae were green and filamentous algae, which are a nuisance for beach tourism in the area, and the invasive species Codium fragile ssp. tomentosoides. Effective management of human access to artificial habitats is essential, since recreational exploitation influences the distribution and structure of their associated assemblages, ultimately affecting the native characteristics of the areas.
\end{abstract}

KEY WORDS: Artificial habitats - Benthic assemblages · Coastal protection · Codium fragile ssp. tomentosoides $\cdot$ Disturbance $\cdot$ Human harvesting $\cdot$ Macroalgae $\cdot$ Mussel beds

\section{INTRODUCTION}

Man-made structures have become ubiquitous features of coastal landscapes. Artificial hard substrata now cover over half of the natural shoreline in some regions (e.g. Meinesz et al. 1991, Cencini 1998, Davis et al. 2002), and their extent will increase in the future (Glasby \& Connell 1999). Proliferation of man-made structures can have substantial consequences on native coastal environments and assemblages, ultimately changing the type and distribution of species and disturbing regional species diversity (Connell \&
Glasby 1999, Glasby \& Connell 1999, Davis et al. 2002, Bacchiocchi \& Airoldi 2003, Chapman 2003, Chapman $\&$ Bulleri 2003). Knowledge of the ecology of these artificial habitats is required for sustainable management (Airoldi et al. 2006). So far, little attention has been given to interactions of man-made structures with regional environmental and societal components.

Urban structures are affected by high anthropogenic disturbances, including recreational activities (Rebele 1994). This is especially true for coastal defence structures, such as sea walls, breakwaters and groynes. These structures, built to control erosion and flooding 
of high value coastlines and infrastructures, represent islands of hard-bottom substrata within prevailing muddy or sandy depositional environments. Artificial substrata do not function as perfect analogues to natural rocky reefs (Glasby 1999, Connell 2001, Chapman 2003, Bulleri \& Chapman 2004, Moschella et al. 2006), but they attract and support assemblages of macroalgae, invertebrates, and fishes typical of rocky shores (Southward \& Orton 1954, Davis et al. 2002, Bacchiocchi \& Airoldi 2003, Dethier et al. 2003). These assemblages are attractive to people because they can be harvested, fished, and are enjoyable when snorkelling. This, plus the fact that coastal defences are generally built along heavily populated coastlines and are rather easily accessible, explains why these structures are popular recreation sites, and tend to be frequently disturbed by species removal and trampling.

Recreational exploitation is one of the most important factors shaping assemblages on natural rocky shores in urban areas (e.g. Durán \& Castilla 1989, Kingsford et al. 1991, Dye 1992, Addessi 1994, Fanelli et al. 1994, Keough \& Quinn 1998, Murray et al. 1999, Moreno 2001, Majiza \& Lasiak 2002). Humans selectively collect organisms for consumption or other purposes, or accidentally damage them by trampling, affecting the structure, the diversity, and the spatial and temporal variability of the assemblages (Boalch et al. 1974, Lindberg et al. 1998, Castilla 1999, Fraschetti et al. 2001, De Boer et al. 2002, Milazzo et al. 2004). The exploitation of assemblages is also common on man-made structures; this phenomenon affects not only structures specifically designed to provide alternative fishery sources and recreation sites, such as artificial reefs, but also structures designed for a different purpose, such as coastal defences, jetties or harbour walls (Collins et al. 1994). Despite the exploitation and recreational potential of artificial habitats, surprisingly limited attention has been paid to societal aspects. Research has focussed on the initial effects of artificial habitats on recruitment, succession, distribution and abundance of associated species, particularly those of economic importance (e.g. Ardizzone et al. 1996, Page et al. 1999, Abelson \& Shlesinger 2002, Choi et al. 2002), whilst limited information is available on the subsequent impacts of human exploitation, either recreational or commercial (but see Guidetti et al. 2005).

The interpretation and prediction of the effects of human exploitation on coastal environments require knowledge of the activities undertaken, their spatial and temporal scales and their effects on target assemblages (Kingsford et al. 1991, De Boer et al. 2002). Patterns and effects of human activities were investigated on coastal structures along about $40 \mathrm{~km}$ of shoreline in the Emilia Romagna region (North Adri- atic Sea, Italy). The economy of this region relies on beach tourism, and human pressure on the coast has been historically intense (Cencini 1998). Protection schemes (mainly groynes and offshore breakwaters) are present along over $60 \%$ of the coastline (Cencini 1998). Human access and collection of organisms, both recreational and commercial, are formally banned on most of the structures. Enforcement is, however, lax, and the structures are visited by recreational shellfish gatherers, anglers, snorkellers and those on holiday, as well as some illegal artisanal fishermen. Previous studies (Bacchiocchi \& Airoldi 2003, L. Airoldi et al. unpubl. data) suggested that such human activity probably altered the structure of epibiota, but no quantitative information was available on the nature, intensity, and spatial and temporal variability of human exploitation and their ecological effects.

Observations during 1999 and 2000 identified the type of human activities carried out on the structures and the target organisms affected. In 2001 and 2002, 4 quantitative studies were conducted to estimate the magnitude and frequency of exploitation by people, and to establish whether the intensity of human exploitation varied over space and time depending on several factors (i.e. tide, season, day of week, time of day, location) that had been reported as important in studies on intertidal rocky shores (Kingsford et al. 1991, Majiza \& Lasiak 2002). Finally, in 2003 and 2004, an experiment involving the removal of mussels to mimic human harvesting was carried out to identify the effects of mussel exploitation on epibiota.

\section{MATERIALS AND METHODS}

Study area and assemblages. The studies and experiments were carried out at 5 locations along the coasts of the province of Ravenna (Fig. 1). The area is subject to moderate wave action and to a tidal range over $80 \mathrm{~cm}$. Average sea surface temperatures vary between $8^{\circ} \mathrm{C}$ in the winter and $24^{\circ} \mathrm{C}$ in the summer (Artegiani et al. 1997), with peaks well above and below these values close to the coastline. Tourism at seaside resorts has developed on a massive scale during the last $30 \mathrm{yr}$ (Cencini 1998). During 2003, for example, visits from over 26 million people were recorded along the coasts of Emilia Romagna, with peaks above 7.7 million during August (Forni \& Malagoli 2004). The coast environment has been degraded from severe development of tourism infrastructure, and beach use is intense, especially during the summer. Other characteristics of the region are described in Bacchiocchi \& Airoldi (2003) and references therein. 


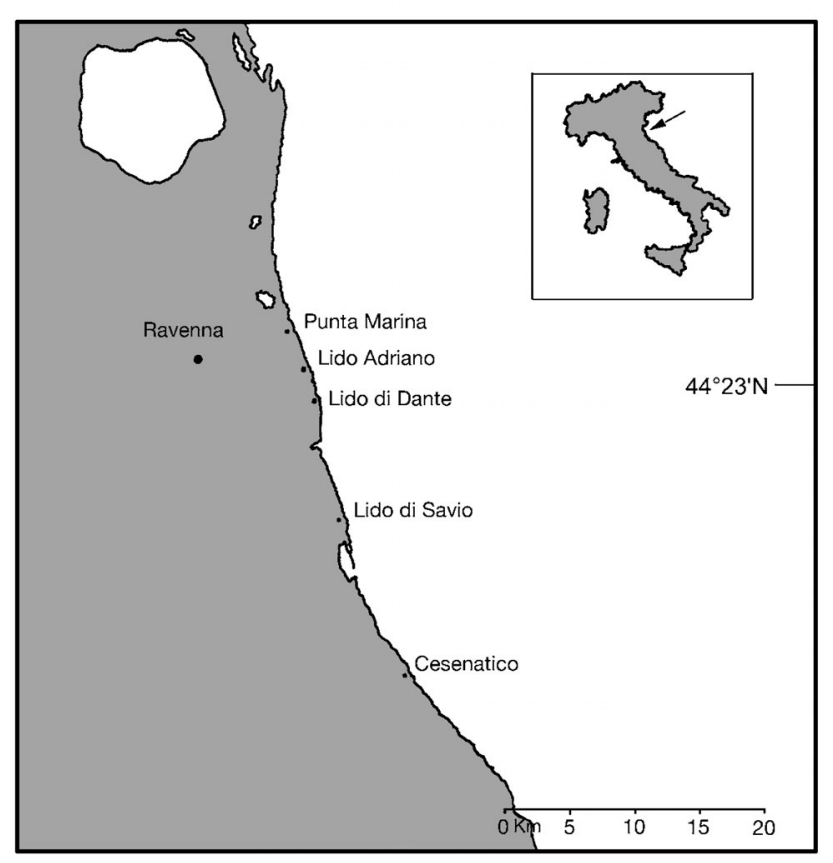

Fig. 1. Map of the study area with locations of the 5 study sites

All the study locations had extensive offshore detached breakwaters, sometimes associated with groynes extending from the shore. At Lido di Dante and Punta Marina, the structures were comprised of low-crested (i.e. crest submerged at high tide) breakwaters, about 180 to $220 \mathrm{~m}$ from the shoreline, as well as groynes. At Lido di Savio, Lido Adriano and Cesenatico, the structures were comprised of only highcrested (i.e. crest always emerged) breakwaters, at approximately 80, 150 and $220 \mathrm{~m}$ from the shore, respectively. Breakwaters protected about $770 \mathrm{~m}$ of the coast at Lido di Dante, whilst at the other locations protection schemes covered up to more than $4 \mathrm{~km}$. All the structures were built with large blocks of quarried rock (mainly limestone), and set on shallow sediments, with a maximum depth of about $3 \mathrm{~m}$ at the seaward sides of breakwaters. People accessed structures either on foot, by swimming or by the use of little boats. While access to groynes is allowed, the law bans access to breakwaters.

The structures supported assemblages dominated by mussels (Mytilus galloprovincialis), oysters (Ostrea edulis and the non-indigenous Crassostrea gigas) and green algae, mainly Ulva intestinalis and the nonindigenous Codium fragile ssp. tomentosoides. Limpets (Patella caerulea) and crabs (including Pachygrapsus marmoratus and Eriphia verrucosa) were also common. The structures also provided a habitat for a variety of fishes, some of which were targets for recreational anglers and spear fishermen (Table 1). A description of the assemblages can be found in Bacchiocchi \& Airoldi (2003) and Bulleri et al. (2005).

Patterns of human activities. The types of recreational activities and the organisms exploited were recorded during preliminary qualitative surveys in 1999 and 2000, at several locations along the coast. Activities were categorized into 4 main groups: harvesting of shellfish from the coastal structures, fishing, collection of clams from the sediments, and no-take activities (Table 1). Our quantitative studies concentrated on the first 2 groups, which were strictly related to the presence of the structures and had a direct impact on their associated assemblages.

Four studies were designed to count the people harvesting or fishing on the structures and to assess spatial and temporal variation in such activities (Table 2). Each person collecting organisms from the coastal structures or fishing was counted, and the type of structure (i.e. groyne or breakwater) was recorded. Whenever possible, we requested information from the people visiting the structure via a questionnaire; it contained questions regarding the amount and type of organisms caught, time spent harvesting or fishing, whether such activity was regular or occasional, preferential position on the structure (i.e. landward or seaward sides of the breakwaters), along with some personal information (e.g. age, sex, nationality, residency). People were reluctant to be interviewed, as activities were illegal, and information was interpreted with caution. On some occasions, the substrata in the immediate areas of people harvesting mussels were examined directly, to estimate the size and magnitude of the disturbance to mussel beds.

Studies 1 to 3 were carried out at Lido di Dante between November 2001 and November 2002. The goal was to assess whether counts of people harvesting or fishing on the structures varied with time of day (morning, midday and afternoon), state of the tide (low and high), or day of the week (weekdays and weekends). For each study, sampling was replicated several times within each of winter, spring, summer and autumn, in order to assess whether patterns observed as a function of the above 3 factors were consistent across season. Replicates consisted of 4 independent countings of people on the structures (both breakwaters and groynes for a total length of about $900 \mathrm{~m}$ ) on randomly chosen days representing the different conditions of season, tide, time of day and day of the week (see Table 2). Days of rough weather were avoided, since preliminary surveys indicated that human activity would be scarce. A total of 112 observations were carried out during the 3 studies. The length of each observation was $2 \mathrm{~h}$.

Study 4 was carried out in May and August 2002 at 4 locations selected at random (among 7 available) along 
the coast: Punta Marina, Lido Adriano, Lido di Savio, and Cesenatico. The study tested whether counts of people harvesting or fishing on the structures varied among locations, and whether spatial patterns were consistent between times of the year with different beach users. Preliminary surveys had suggested that people visiting the shore in the spring were mainly locals, while in the summer more tourists were present. For this study, sampling was restricted to the breakwaters, as groynes were only present at Punta Marina. Sampling was carried out early in the morning, and was replicated 5 times in each of May and August. Each time, all locations were sampled by each of 4 randomly allocated observers. Replicates were independent counts of people on about $300 \mathrm{~m}$ of structures. The period of observation for each replicate was $2 \mathrm{~h}$.

Data for the first 3 studies were analyzed using 2-way ANOVAs, with season (4 levels) orthogonal to time of day (3 levels), tide (2 levels) or day of week (2 levels). Data from study 4 were analyzed using a 2-way ANOVA with location (5 levels) orthogonal to month (2 levels). Before running the analyses, data were logarithmically transformed, which always successfully stabilized variances (Cochran's $C$-tests, $\mathrm{p}>0.05$ ).

Effects of mussel harvesting. An experiment was carried out at Cesenatico to quantify the impact of mussel harvesting on dominant epibiota. It was designed to test whether effects were consistent between the landward and seaward sides of breakwaters and between nearby breakwaters. The experiment was set up on both the landward and seaward sides of each of 3 breakwaters, selected at random, about 100 to $600 \mathrm{~m}$ apart. For each side, 8 blocks about $1 \mathrm{~m}^{3}$, located from -20 to $+30 \mathrm{~cm}$ relative to mean-low-water and extensively covered (>80\%) by mussels of harvestable size were permanently marked by securing stainless steel bolts with marine epoxy into drilled holes. Blocks were randomly allocated to either mussel harvesting (hereafter 'harvesting') or unmanipulated (hereafter 'control') treatments; there were 4 of each. Treatments were applied in August 2003, as observations indicated that this is the time of the year when harvesting is most intense. Mussels were removed from harvesting blocks by using shovels, knives and chisels, in order to mimic as close as possible the observed changes caused by harvesters. Control blocks were left untouched. The resulting harvested surfaces appeared as patches of bare rock with sparse covers of byssal thread, and the remains of a few barnacles and macroalgae.

In the study area, although some species settle late in the summer or early autumn, recruitment and growth of species become generally visible in the spring (Bacchiocchi \& Airoldi 2003, L. Airoldi et al. unpubl. data). The effects of harvesting on the epibiota were thus quantified during the following May (2004), when growth of species peaked and human disturbance from the subsequent holiday season was still relatively low. For each block, sampling was replicated in four $20 \times 20 \mathrm{~cm}$ plots. Abundance (on both primary and secondary substrata) of dominant epibiota, and space not occupied by visible macroscopic organisms were quantified visually as percent covers (Benedetti-Cecchi et al. 1996). A frame divided into a grid of 25 sub-quadrats was used, and a score from 0 to $4 \%$ was given to each taxon in each square. Species present with $<1 \%$ cover were given an arbitrary value of $0.5 \%$.

The responses of epibenthic assemblages were examined by multivariate analyses on a total of 10 response variables (see Results). Data were 4th-root transformed, to retain information regarding the relative abundance whilst at the same time reducing the difference in scale among the variables (Clarke 1993). Principal coordinate analysis (PCO; Anderson 2003 and references therein) was performed to produce a distance matrix of the centroids of each block in BrayCurtis space, which was used as input to the subsequent multivariate analyses. A plot of the first 2 principal coordinate axes was used to visualize patterns of overall dispersion of assemblages on blocks. In addition, a canonical analysis of principal coordinates (CAP; Anderson \& Willis 2003) was performed to visualize patterns of dispersion as a function of harvesting effects (using the a priori groupings of mussel harvesting and control for the explanatory matrix) and side of breakwater (using the a priori groupings of landward and seaward sides). Effects were tested statistically by using permutation 3-way multivariate analysis of variance (PERMANOVA, formerly NPMANOVA, Anderson 2001a), with harvesting (fixed, harvesting vs. control), side (fixed, landward vs. seaward) and breakwater (random, 3 levels) as orthogonal factors. For the analyses, 4999 unrestricted random permutations of the raw data were used to generate p-values (Anderson 2001b).

Responses of total macroalgae, mussels and space not occupied by macroscopic organisms were further examined by univariate 4 -way ANOVAs. Factors were: harvesting (fixed, harvesting vs. control), side (fixed, landward vs. seaward) and breakwater (random, 3 levels), orthogonal to each other, and block (random, 4 levels) nested in the interaction of the previous 3 factors. Pooling procedures were used when appropriate to increase the power of the test for harvesting as in Underwood (1997). The assumption of homogeneity of variances was checked with Cochran's $C$-tests, and was always fulfilled ( $p>0.05$ ), except for unoccupied space. Such heterogeneity could not be removed through transformation of data; since the data set was 
large and balanced, the analysis was done in any case and results were interpreted conservatively, using $\mathrm{p}=$ 0.01 as the level of significance (Underwood 1997).

\section{RESULTS}

\section{Human activities and organisms affected}

Coastal structures were the target of recreational activities, which involved the illegal exploitation of species (Table 1). Few people visited coastal defence structures, and particularly breakwaters, for recreational no-take activities, probably because of poor accessibility and precarious footing on the steep and slippery surfaces of the blocks. Mussels were by far the organisms most often harvested, followed by oysters, crabs, limpets and shrimps (Table 1). Shellfish was mostly collected as food, although mussels and limpets were sometimes used as bait for fishing. The following fishes, Mugil spp., Lithognathus mormyrus, Boops boops, Solea solea, Bothus spp., Trachinus draco, Gobius paganellus and Dicentrarchus labrax were among the most frequently caught (Table 1). Interviews and direct observations suggested that on average approximately $2.5 \mathrm{~kg}$ of mussels or $1 \mathrm{~kg}$ of fish or crabs were collected per person each time. Harvesting opened large patches within mussel beds, ranging from approximately 1 to several $\mathrm{dm}^{2}$.

\section{Spatial and temporal patterns}

A total of 145 people were observed harvesting sessile organisms and 155 were observed fishing on the coastal structures during the $304 \mathrm{~h}$ of observation at our study sites. Most people were local males, but the percentage of tourists and females increased over the summer. At Lido di Dante, where both groynes and breakwaters were present, over $70 \%$ of the people preferentially exploited groynes, because they were more easily accessible. The most illegal activities (e.g. collection of mussels for local restaurants, fishing with nets or collection of large quantities of organisms) were, however, confined to the breakwaters, and were often carried out at dawn or during the night. The reluctance of people to answer the questionnaire meant we could not identify clear patterns of shellfish harvesting as a function of position on the structures. Our observations, however, suggest that mussel harvesting was most intense at the landward side of breakwaters at low shore levels, while at the seaward side mussels were most often collected from shallow subtidal habitats (e.g. from semi-artisanal divers).

The number of people harvesting shellfish on groynes and breakwaters at Lido di Dante was consistently greatest in summer, resulting in season having a significant effect in Studies 1 to 3 (Fig. 2, Table 3). Few people were on the structures during the autumn and winter. During spring and summer, there was high day to day variability among patterns of human harvesting, which resulted in a high residual variance that masked some of the differences related to time of day, state of the tide and day of the week (Table 3). Although there were no statistically significant effects of these 3 factors, some trends were evident, and consistent with our preliminary observations carried out in 1999 and 2000. Most people harvested at midday in the spring, while in the summer people most harvested in the morning and afternoon (Fig. 2, Study 1). More people were observed during low tide in the spring, while no differences were observed between low and high tide in the summer (Fig. 2, Study 2). Overall, more people collected shellfish during weekends than weekdays (Fig. 2, Study 3). Conversely, no significant differences were observed in the number of people harvesting shellfish on break-
Fig. 2. Number of people harvesting shellfish on breakwaters and groynes during 4 seasons ( $\mathrm{W}=$ winter, $\mathrm{SP}=$ spring, $\mathrm{SU}=$ summer, $\mathrm{A}=$ autumn) over 2001 and 2002 at Lido di Dante as a function of (a) time of day (Study 1), (b) tide (Study 2), and (c) day of the week (Study 3); and (d) number of people harvesting shellfish on breakwaters at 4 different locations $(\mathrm{PM}=$ Punta Marina, LA = Lido Adriano, LS = Lido di Savio, and CS = Cesenatico) during May and August 2002 (Study 4). Data are average counts over $2 \mathrm{~h}(+1 \mathrm{SE}, \mathrm{n}=4$ for Studies 1 to $3, \mathrm{n}=5$ for Study 4). For further details see Table 2 
Table 3. Results of ANOVAs and SNK tests on log-transformed numbers of people harvesting shellfish or fishing on coastal defence structures during the 4 studies. Cochran's $C$-tests for homogeneity was not always significant $(p>0.05)$. Significant $p$-values $(p<0.05)$ are shown in bold type. Factors for each study are as in Table 2

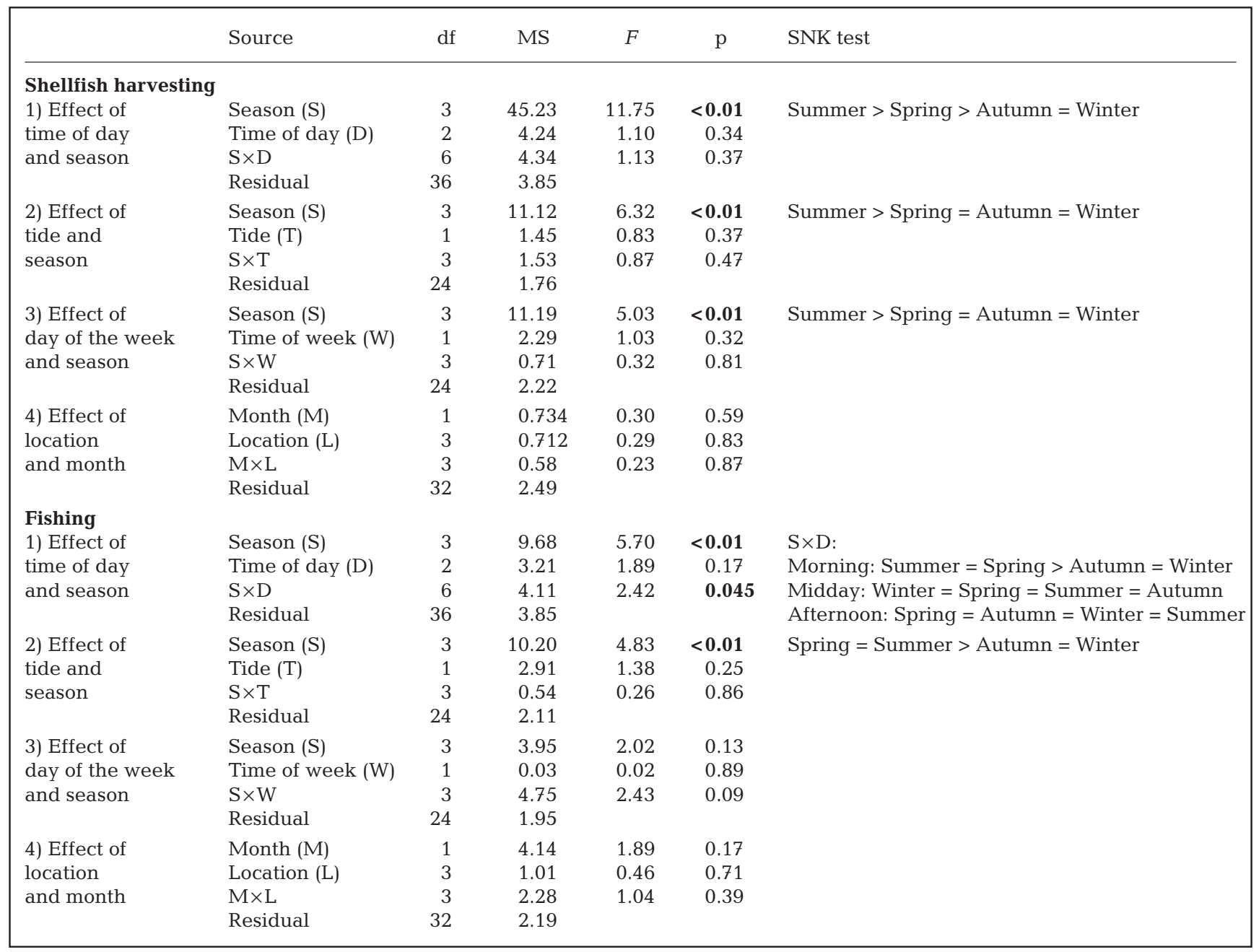

waters among different locations along the Emilia Romagna coast (Fig. 2, Table 3, Study 4). This was unexpected; breakwaters were located at different distances from the coast, thus exploitation might have been most intense at structures closest to the shoreline. Density of visitors was also similar between May and August (Fig. 2, Table 3, Study 4), suggesting that mainly local people exploited breakwaters, whilst tourists made a minor impact, which is supported by the interviews.

At Lido di Dante, numbers of recreational fishermen were relatively constant across seasons at midday and in the afternoon, but varied in the morning (Fig. 3, Table 3, Study 1). Fishing was most frequent during the morning in the summer and often in the spring, while no fishing activity was recorded before midday in the winter and autumn. Overall, there was a trend for a greater number of people to be fishing during the spring and summer than during the autumn and winter, resulting in season having a significant effect in Studies 1 and 2 (Fig. 2, Table 3). No consistent patterns in fishing activities were observed as a function of tide or day of the week (Fig. 3, Table 3, Studies 2 and 3). Few differences were observed in the number of people fishing from the breakwaters at different locations along the coast, both in May and August (Fig. 3, Study 4).

\section{Effects of mussel harvesting on epibiota}

The variables included in the multivariate analyses were: Ulva intestinalis, filamentous algae, and Codium fragile spp. tomentosoides (subsequently lumped as 'macroalgae' for univariate analyses as they showed similar responses to treatments), Mytilus galloprovin- 

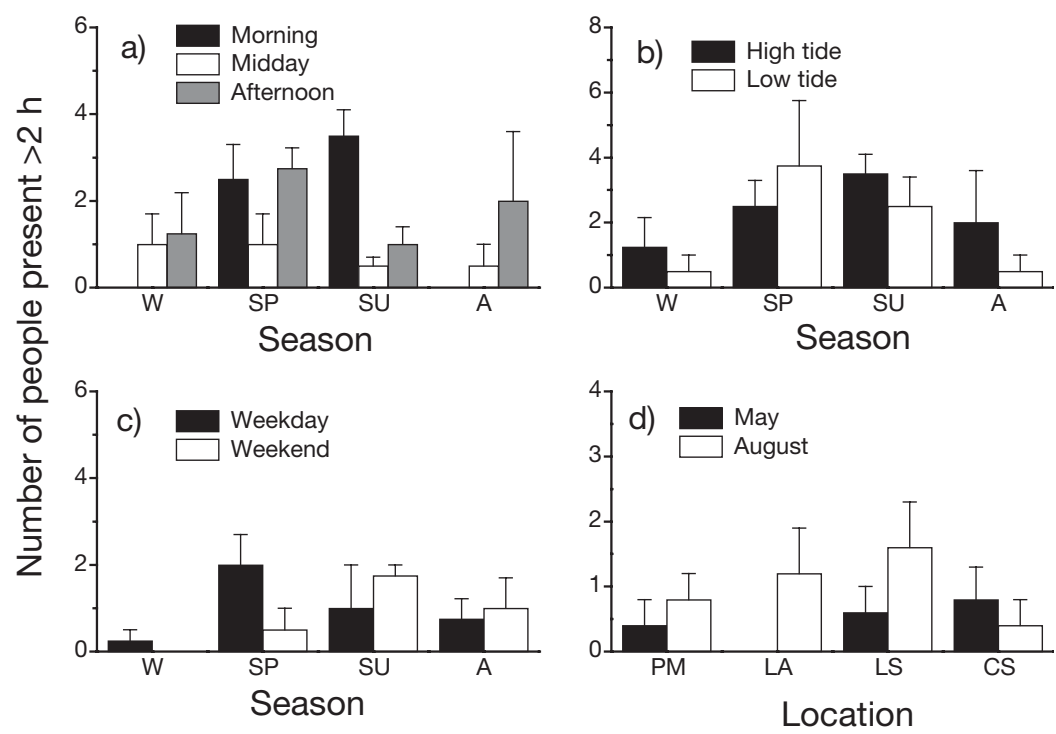

Fig. 3. Number of people fishing on breakwaters and groynes during 4 seasons (W = winter, $\mathrm{SP}=$ spring, $\mathrm{SU}=$ summer, $\mathrm{A}=$ autumn) over 2001 and 2002 at Lido di Dante as a function of (a) time of day (Study 1), (b) tide (Study 2) and (c) day of the week (Study 3); and (d) number of people fishing on breakwaters at 4 different locations $(\mathrm{PM}=$ Punta Marina, $\mathrm{LA}=$ Lido Adriano, $\mathrm{LS}=$ Lido di Savio, and $\mathrm{CS}=$ Cesenatico) during May and August 2002 (Study 4). Data are average counts over $2 \mathrm{~h}(+1 \mathrm{SE}, \mathrm{n}=4$ for Studies 1 to $3, \mathrm{n}=5$ for Study 4$)$. For further details see Table 2
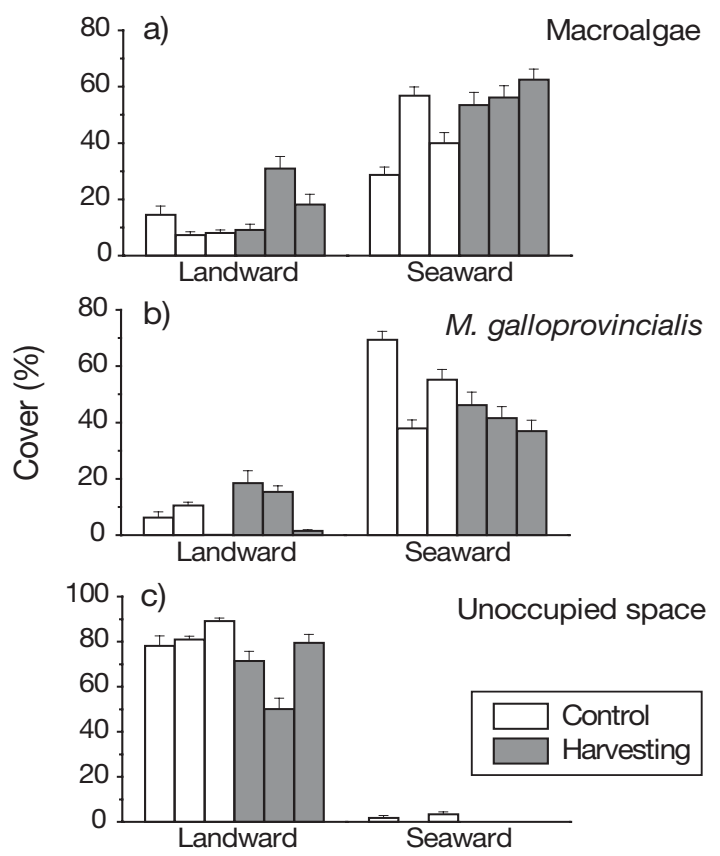

Fig. 4. Effects of experimental harvesting of mussels (in August 2003) on covers of (a) total macroalgae (Ulva intestinalis, filamentous algae and Codium fragile spp. tomentosoides), (b) mussels (Mytilus galloprovincialis) and (c) unoccupied space (bare rock, silt and a thin coating of microorganisms) on the landward and seaward sides of each of 3 manipulated and unmanipulated breakwaters at Cesenatico in May 2004. Data are average covers over 4 blocks per breakwater and 4 quadrats per block $(+1 \mathrm{SE}, \mathrm{n}=16)$ cialis, oysters, unidentified sponges, unidentified barnacles, and 3 types of rock not occupied by macroscopic organisms, specifically, rock covered by a thin coating of silt, rock covered by a thin coating of unidentified microalgae and/or other microorganisms, and apparently bare rock (subsequently lumped as total 'unoccupied space' for univariate analyses as they showed similar responses to treatments). Macroalgae and mussels were particularly abundant at the seaward sides of the breakwaters, whilst a high proportion (often above $70 \%$ ) of unoccupied space characterized the landward sides (Fig. 4). These differences between landward and seaward sides of breakwaters resulted in consistent significant effects for the factor side in all the analyses, both multivariate (Table 4) and univariate (Table 5).

In May 2004, 10 mo after the start of the experiment and before the new intensive harvesting season, assemblages still differed significantly between harvested and control blocks. Differences were particularly evident at the seaward sides of breakwaters compared to the landward sides, which resulted in a significant interaction, harvesting $\times$ side (Table 4 ). The significant differences found by the PERMANOVA test were not illustrated clearly in the principal coordinate plot (Fig. 5a); this is likely because the axis of real group differences that occurred in multivariate space was not in the same direction as the maximum variation. The plot of the 2 canonical axes corresponding to the main effects of harvesting and side,

Table 4. Results of permutation multivariate analysis of variance (PERMANOVA) on Bray-Curtis dissimilarities for assemblages on breakwaters after 4th-root transformation. Factors were: harvesting (fixed, harvesting vs. control), side (fixed, landward vs. seaward) and breakwater (random, 3 levels). Significant effects $(p<0.05)$ are in bold

\begin{tabular}{|lrrrr|}
\hline Source & df & MS & $F$ & $p$ (perm) \\
\hline Harvesting (H) & 1 & 0.0928 & 18.5673 & $\mathbf{0 . 0 1 4 8}$ \\
Side (S) & 1 & 1.1679 & 2.4352 & $\mathbf{0 . 0 4 5 4}$ \\
Breakwater (B) & 2 & 0.4709 & 8.7104 & $\mathbf{0 . 0 0 0 2}$ \\
$\mathrm{H} \times \mathrm{S}$ & 1 & 0.1285 & 4.1533 & $\mathbf{0 . 0 3 1 0}$ \\
$\mathrm{H} \times \mathrm{B}$ & 2 & 0.0050 & 0.0924 & 0.9992 \\
$\mathrm{~S} \times \mathrm{B}$ & 2 & 0.4796 & 0.8722 & $\mathbf{0 . 0 0 0 2}$ \\
$\mathrm{H} \times \mathrm{S} \times \mathrm{B}$ & 2 & 0.0310 & 0.5726 & 0.8118 \\
Residual & 36 & 0.0541 & & \\
\hline
\end{tabular}


Table 5. Results of ANOVAs on covers of total macroalgae (raw data), Mytilus galloprovincialis (raw data), and unoccupied space (log-transformed data). Factors are: breakwater (random, 3 levels), side (fixed, landward vs. seaward), harvesting (fixed, harvesting vs. control) and block (random, 4 levels, nested in the interaction of the other 3 factors). Cochran's $C$-tests were not significant $(\mathrm{p}>0.05)$ except for unoccupied space $(\mathrm{p}<0.01)$. Significant effects $(\mathrm{p}<0.05$ for total macroalgae and M. galloprovincialis, $\mathrm{p}<0.01$ for unoccupied space) are in bold. For further explanations see text

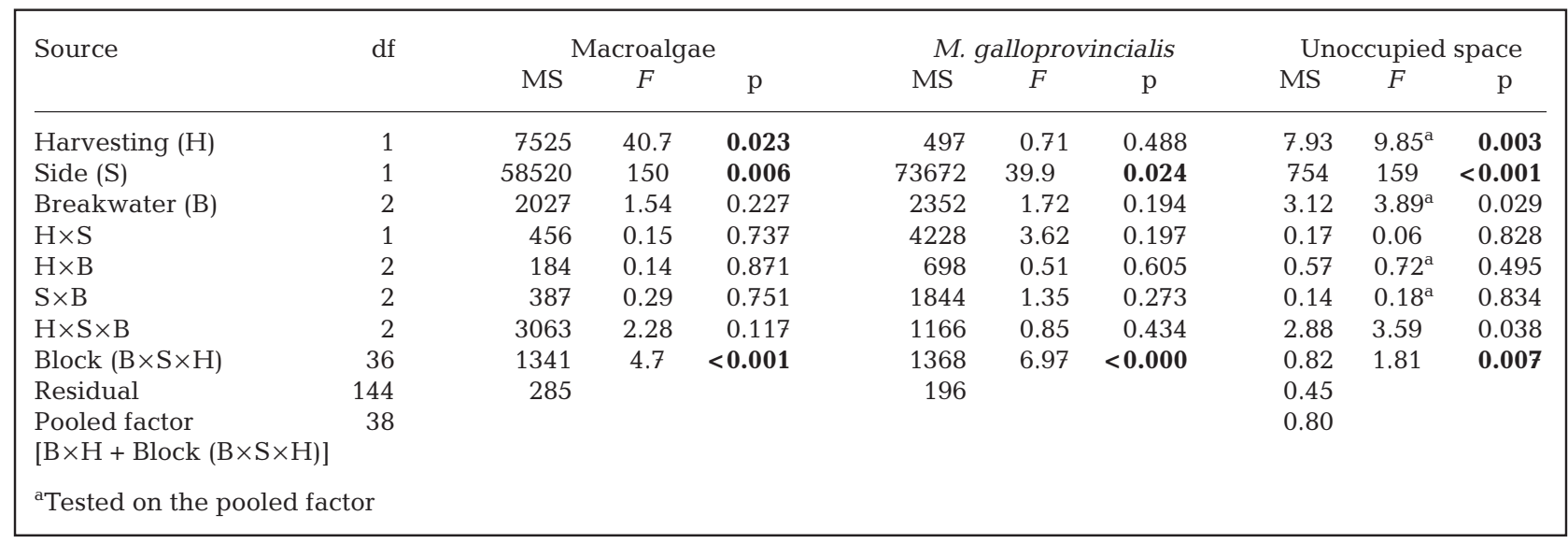

however, clearly showed a significant interaction between them (Fig. 5b).

Differences between harvested and control blocks were further explained by univariate analyses on macroalgae, Mytilus galloprovincialis, and unoccupied space. Oysters, sponges and barnacles were too sparse for further meaningful analyses. Macroalgae flourished on the breakwaters, particularly on the seaward exposed sides, with peak covers above $60 \%$ (Fig. 4). Macroalgal cover expanded when mussels were harvested, with average values of $39 \%$ in harvested blocks and $25 \%$ in control blocks (Fig. 4). This increase was detected as significant despite the variability in macroalgal cover between blocks (Table 5), and was consistent between both the landward and seaward sides of breakwaters and between breakwaters.

The abundance of mussels in control blocks was lower than at the beginning of the experiment (Fig. 4), because violent storms during the autumn and winter struck the breakwaters and extensively damaged the mussel beds (authors' unpubl. data). Their effects on mussels were particularly severe at the landward side of the breakwaters, and probably masked some of the effects of recreational harvesting (see 'Discussion'). By May, cover of mussels at harvested and control blocks on the landward sides of the structures had reached comparable values (Fig. 4). On the seaward sides mussels were on average more abundant in control

\section{a: principal coordinate plot}

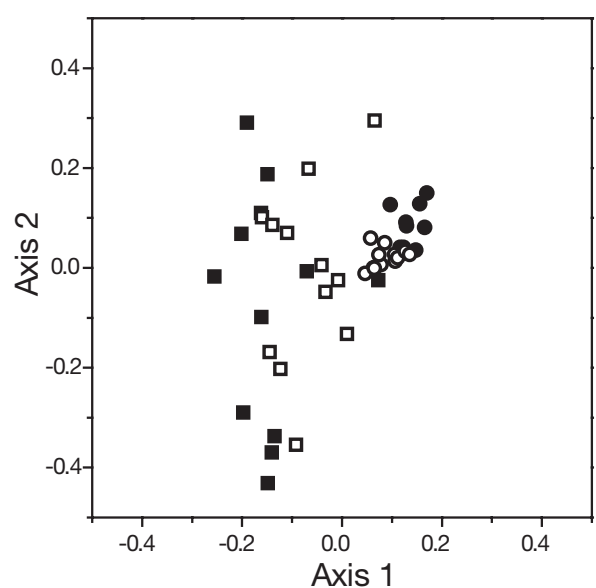

\section{b: canonical plot}

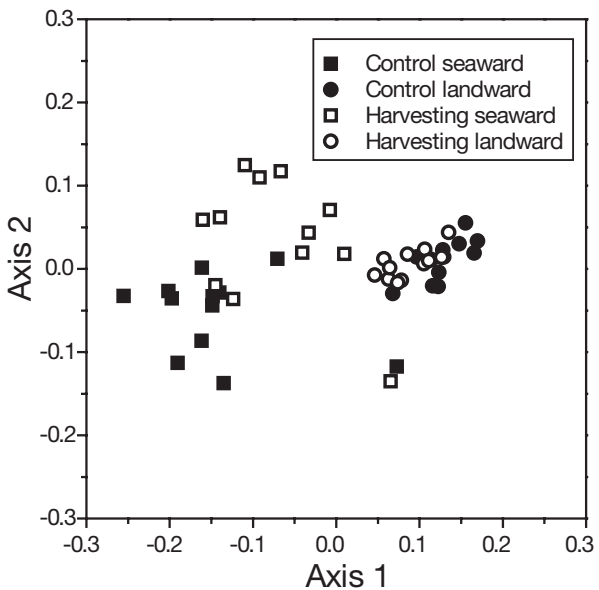

Fig. 5. Two-dimensional plots of the (a) principal coordinate axes (unconstrained metric multi-dimensional scaling) and (b) canonical axes of principal coordinates showing ordination of centroids of assemblages on breakwaters in each combination of harvesting vs. control treatment and landward vs. seaward sides ( $\mathrm{n}=12,4$ blocks for each of 3 breakwaters). Analyses were based on Bray-Curtis dissimilarities after 4th-root transformation 
(54\% cover) than in harvested ( $41 \%$ cover) blocks, but patterns were variable over space and this difference was not significant (Table 5).

At the landward sides of breakwaters there was a large amount of unoccupied space, much of it coated with silt and/or microorganisms. This unoccupied space was produced both by the experimental harvesting of mussels and by the subsequent effects of storms. By May, unoccupied space was less abundant in harvested than control blocks (Fig. 4), probably as a consequence of the growth of macroalgae in harvested treatments. Although at the seaward sides of breakwaters the amount of unoccupied space was small, a similar trend was observed, which resulted in a significant main effect of the harvesting factor (Table 5).

\section{DISCUSSION}

The present study shows that disturbance from exploitation has large effects on assemblages of coastal defence structures, and should be taken into account when explaining their structure and variability. Assemblages on these and other types of artificial structures are, in fact, shaped and dependent on human interventions; ignoring human perturbations in such systems could lead to misleading conclusions about their functioning and performance.

Recreational exploitation was a major and recurrent source of disturbance for the assemblages on defence structures along the highly populated coasts of EmiliaRomagna. Hundreds of people visited the structures for recreational fishing and to harvest a variety of invertebrates to be used as food or, to a lesser extent, as bait. A legal ban did not act as a deterrent, rather it confined the most illegal activities to dawn or night. Different from rocky shores in other parts of the world (e.g. Kingsford et al. 1991, Addessi 1994, Keough \& Quinn 1998), few people visited the structures, and particularly breakwaters, for recreational no-take activities.

Human exploitation was most intense during the spring and summer, and activities that required immersion in the water, such as mussel harvesting, were restricted to the warmest months. Density of visitors varied at small temporal scales, but relationships with time of day, state of the tide or day of the week were not obvious. Exploitation was evenly distributed among different locations along the coast, despite marked differences in the accessibility of the structures. Distance from the shore was probably not a limiting factor for local people, who were the main exploiters. Furthermore, breakwaters more distant from the shore are an ideal place to carry out unlawful activities since they are more difficult to observe, thus possibly compensating the major efforts required to reach the structures.

The estimates of sessile species, fish and crabs collected per person, along with the counts of total harvesters, clearly demonstrate the dramatic levels of disturbance to assemblages on coastal structures in this region. For example, at Lido di Dante, during the summer, an average of 3 people were observed harvesting shellfish on the structures every $2 \mathrm{~h}$ from 08:00 to 18:00 h, independently of time of day, day of the week or tidal conditions (Fig. 2), which gives an estimate of 15 people $\mathrm{d}^{-1}$. Considering that about $80 \%$ of those people collected mussels, and that on average each person harvested about $2.5 \mathrm{~kg}$ of mussels, we estimate that $\sim 2.7$ tons of mussels are collected over each summer on the coastal structures at Lido di Dante alone. Measures of mussel biomass per unit surface in June 2003 (F. Bacchiocchi unpubl. data) indicate an average wet weight of $188 \mathrm{~g} \mathrm{dm}^{2}(\mathrm{n}=70$, $\mathrm{SD}=104)$. Thus, 2.7 tons of harvested mussels would roughly correspond to a disrupted surface of $\sim 144 \mathrm{~m}^{2}$. This estimate is limited to a band of $\sim 20 \mathrm{~cm}$ in height across low shore and shallow subtidal habitats, where mussels are an edible size and easy to collect; this does not include people collecting mussels overnight by diving at deeper habitats.

Harvesting of mussels over the summer led to depletion of mussel beds, opening of unoccupied space and patchiness in the assemblages, ultimately favouring the development of green and filamentous algae, including the invasive Codium fragile ssp. tomentosoides. The effects of mussel harvesting were still notable after almost $1 \mathrm{yr}$ from the beginning of the experiment. Differences were marked on the seaward sides of breakwaters; on the landward sides, effects were partially masked by the action of storms during the autumn and winter, which damaged mussel beds on the structures. Damage was particularly severe on the landward side of breakwaters compared to the seaward sides, probably because mussel beds at these sheltered habitats were multi-layered, thus more subject to the risk of dislodgement by waves (Harger \& Landenberger 1971, Paine \& Levin 1981). It is also possible that mussel beds were particularly susceptible to storms after being weakened by intensive harvesting; the compactness of mussel beds can, in fact, be compromised by the removal of even a few individuals (Denny 1987), and a number of small disturbed points may coalesce to produce larger patches (Paine \& Levin 1981). A 'human-exclusion' experiment (e.g. Castilla 1999) would be necessary to test whether human harvesting can enhance the susceptibility of mussel beds to wave dislodgement. We attempted such an experiment in 2002. As legislative protection was lax, the experiment had to rely on the voluntary abstention of 
people from harvesting at certain sites. Despite the use of explanatory signs at both the breakwaters and beach establishments, people's collaboration was minimal, and the experiment was abandoned.

The exploitation of assemblages on man-made structures as sources of harvestable biomass of macroalgae, shellfish and fishes is also a common phenomenon in other coastal areas (Collins et al. 1994). Our results emphasize the need for effective management of such human disturbances to urban coastal structures. These habitats attract 'artificial' assemblages that are often extraneous to the native characteristics of the areas and that can disturb regional species diversity and introduce non-native or nuisance species (Glasby \& Connell 1999, Lambert \& Lambert 2003, Airoldi et al. 2005). Thus, any factor influencing the type and distribution of organisms on man-made structures requires careful consideration of its ultimate effects on native environments. For example, the proliferation of hard coastal structures along the sandy coasts of Emilia Romagna has promoted the expansion of a number of extraneous species, including the pest alga Codium fragile ssp. tomentosoides (Bulleri et al. 2005, Bulleri \& Airoldi 2006). Further, flourishing of algae on the structures is a problem for local tourism. Algae are torn off and wash onto the beaches, thereby reducing the beaches perceived amenity; they also need to be removed periodically, this adds costs to local municipalities. Although the growth of Codium and other algae is an unavoidable consequence of the presence of the structures, disturbance to mussel beds indeed facilitates their growth. Limiting human exploitation would help control the abundance and spread of these nuisance species; thus, there are substantial environmental and socioeconomic reasons why an effective regulation of human visits to the structures would be desirable.

Clearly, the management of recreational activities on defence structures along the coasts of Emilia Romagna has not received appropriate attention, and the almost complete absence of visible enforcement contributes to the high frequency of unlawful visitations. Advice that recreational activities should be regulated more effectively has also been proposed for natural rocky shores (e.g. Fanelli et al. 1994, Murray et al. 1999, Keough \& Quinn 2000). Although the nature, scale and consequences of recreational exploitation substantially differ between man-made and natural hard substrata, human harvesting is a major disturbance for coastal assemblages in both habitats, affecting their distribution and structure. Knowledge of the type, magnitude and variability of such disturbances and recognition of their ecological effects can help to develop policies for managing human exploitation of coastal assemblages.
Acknowledgements. This work was supported by the EU project DELOS (EVK3-CT-2000-00041) and by the project COFIN (ex $40 \%$ ). L.A. was supported by an Assegno di Ricerca of the University of Bologna. We thank J. M. Anderson, F. Bertasi, M. Carrera, F. Colosio, F. Costantini and G. M. Branca for help with the fieldwork, and 4 anonymous reviewers for their careful revision of the manuscript. We are grateful to T. J. Willis for help with the statistical analyses and for insightful comments on an earlier draft.

\section{LITERATURE CITED}

Abelson A, Shlesinger Y (2002) Comparison of the development of coral and fish communities on rock-aggregated artificial reefs in Eilat, Red Sea. ICES J Mar Sci 59:S122-S126

Addessi L (1994) Human disturbance and long-term changes on a rocky intertidal community. Ecology 4:786-797

Airoldi L, Abbiati M, Beck MW, Hawkins SJ and 6 others (2006) An ecological perspective on the deployment and design of low-crested and other hard coastal defence structures. Coast Eng (in press)

Anderson MJ (2001a) A new method for non-parametric multivariate analysis of variance. Austral Ecol 26:32-46

Anderson MJ (2001b) Permutation tests for univariate or multivariate analysis of variance and regression. Can J Fish Aquat Sci 58:626-639

Anderson MJ (2003) PCO: a FORTRAN computer program for principal coordinate analysis. Department of Statistics, University of Auckland, Auckland

Anderson MJ, Willis TJ (2003) Canonical analysis of principal coordinates: a useful method of constrained ordination for ecology. Ecology 84:511-525

Ardizzone GD, Belluscio A, Gravina MF, Somaschini A (1996) Colonization and disappearance of Mytilus galloprovincialis Lam. on an artificial habitat in the Mediterranean Sea. Estuar Coast Shelf Sci 43:665-676

Artegiani A, Bregant D, Paschini E, Pinardi N, Raicich F, Russo A (1997) The Adriatic Sea general circulation. Part II. Baroclinic circulation structure. J Phys Oceanogr 27:1515-1532

Bacchiocchi F, Airoldi L (2003) Distribution and dynamics of epibiota on hard structures for coastal protection. Estuar Coast Shelf Sci 56:1157-1166

Benedetti-Cecchi L, Airoldi L, Abbiati M, Cinelli F (1996) Estimating the abundance of benthic invertebrates: a comparison of procedures and variability between observers. Mar Ecol Prog Ser 138:93-101

Boalch GT, Holme NA, Jephson NA, Sidwell JMC (1974) A resurvey of Colman's intertidal traverses at Wembury, South Devon. J Mar Biol Assoc UK 54:551-553

Bulleri F, Airoldi L (2006) Artificial structures as habitats for non-indigenous species: the case of the green alga, Codium fragile ssp. tomentosoides, in the north Adriatic Sea (North-eastern Mediterranean). J Appl Ecol (in press)

Bulleri F, Chapman MG (2004) Intertidal assemblages on artificial and natural habitats in marinas on the north-west coast of Italy. Mar Biol 185:381-391

Bulleri F, Abbiati M, Airoldi L (2005) The colonisation of artificial human-made structures by the invasive alga Codium fragile ssp. tomentosoides in the north Adriatic Sea (NE Mediterranean). Hydrobiologia (in press)

Castilla JC (1999) Coastal marine communities: trends and perspectives from human-exclusion experiments. Trends Ecol Evol 14:280-283

Cencini C (1998) Physical processes and human activities in the evolution of the Po delta, Italy. J Coast Res 14:774-793 
Chapman MG (2003) Paucity of mobile species on constructed seawalls: effects of urbanization on biodiversity. Mar Ecol Prog Ser 264:21-29

Chapman MG, Bulleri F (2003) Intertidal seawalls-new feautures of landscape in intertidal environements. Landscape Urban Planning 62:159-172

Choi CG, Takeuchi Y, Terawaki T, Serisawa Y, Ohno M, Sohn $\mathrm{CH}$ (2002) Ecology of seaweed beds on two types of artificial reef. J Appl Phycol 14:343-349

Clarke KR (1993) Non-parametric multivariate analyses of changes in community structure. Aust J Ecol 18:117-143

Collins K, Jensen A, Lockwood A, Lockwood S (1994) Coastal structures, waste materials and fishery enhancement. Bull Mar Sci 55:1240-1250

Connell SD (2001) Urban structures as marine habitats: an experimental comparison of the composition and abundance of subtidal epibiota among pilings, pontoons and rocky reefs. Mar Environ Res 52:115-125

Connell SD, Glasby TM (1999) Do urban structures influence local abundance and diversity of subtidal epibiota? A case study from Sydney Harbour, Australia. Mar Environ Res 47:373-387

Davis JLD, Levin LA, Walther SM (2002) Artificial armored shorelines: sites for open-coast species in a southern California bay. Mar Biol 140:1249-1262

De Boer WF, Blijdenstein AF, Longamane F (2002) Prey choice and habitat use of people exploiting intertidal resources. Environ Conserv 29:238-252

Denny MW (1987) Lift as a mechanism of patch initiation in mussel beds. J Exp Mar Biol Ecol 113:231-245

Dethier MN, McDonald K, Strathmann RR (2003) Colonization and connectivity of habitat patches for coastal marine species distant from source populations. Conserv Biol 17: 1024-1035

Durán LR, Castilla JR (1989) Variation and persistence of the middle rocky intertidal community of central Chile, with and without human harvesting. Mar Biol 103:555-562

Dye AH (1992) Experimental studies of succession and stability in rocky intertidal communities subject to artisanal shellfish gathering. Neth J Sea Res 30:209-217

Fanelli G, Piraino S, Belmonte G, Geraci S, Boero F (1994) Human predation along Apulian rocky coasts (SE Italy): desertification caused by Lithophaga lithophaga (Mollusca) fisheries. Mar Ecol Prog Ser 110:1-8

Forni S, Malagoli M (2004) Rapporto annuale sul movimento turistico e la composizione della struttura ricettiva (alberghiera e complementare) dell'Emilia Romagna: anno 2003. Regione Emilia Romagna, Servizio Turismo e Qualità Aree Turistiche della Regione, Bologna

Fraschetti S, Bianchi CN, Terlizzi A, Fanelli G, Morri C, Boero F (2001) Spatial variability and human disturbance in shallow subtidal hard substrate assemblages: a regional approach. Mar Ecol Prog Ser 212:1-12

Glasby TM (1999) Differences between subtidal epibiota on pier pilings and rocky reefs at marinas in Sydney. Estuar Coast Shelf Sci 48:281-290

Glasby TM, Connell SD (1999) Urban structures as marine habitats. Ambio 28:595-598

Editorial responsibility: Otto Kinne (Editor-in-Chief), Oldendorf/Luhe, Germany
Guidetti P, Bussotti S, Boero F (2005) Evaluating the effects of protection on fish predators and sea urchins in shallow artificial rocky habitats: a case study in the northern Adriatic Sea. Mar Environ Res 59:333-348

Harger JRE, Landenberger DE (1971) The effect of storms as a density dependent mortality factor on populations of sea mussels. Veliger 14:195-201

Keough MJ, Quinn GP (1998) Effects of periodic disturbances from trampling on rocky intertidal algal beds. Ecol Appl 8: 141-161

Keough MJ, Quinn GP (2000) Legislative vs. practical protection of an intertidal shoreline in southeastern Australia. Ecol Appl 10:871-881

Kingsford MJ, Underwood AJ, Kennelly SJ (1991) Humans as predators on rocky reefs in New South Wales, Australia. Mar Ecol Prog Ser 72:1-14

Lambert CC, Lambert G (2003) Persistence and differential distribution of nonindigenous ascidians in harbors of the Southern California Bight. Mar Ecol Prog Ser 259:145-161

Lindberg DR, Estes JA, Warheit KI (1998) Human influences on trophic cascades along rocky shores. Ecol Appl 8: $880-890$

Majiza VN, Lasiak TA (2002) The influence of site, season and day of the week on exploitation of rocky intertidal biota in central Transkei, South Africa. S Afr J Mar Sci 24:57-64

Meinesz A, Lefevre JR, Astier JM (1991) Impact of coastal development on the infralittoral zone along the southeastern Mediterranean shore of continental France. Mar Pollut Bull 23:343-347

Milazzo M, Badalamenti F, Riggio S, Chemello R (2004) Patterns of algal recovery and small-scale effects of canopy removal as a result of human trampling on a Mediterranean rocky shallow community. Biol Conserv 117:191-202

Moreno CA (2001) Community patterns generated by human harvesting on Chilean shores. Aquat Conserv 11:19-30

Moschella PS, Abbiati M, Åberg P, Airoldi L and 12 others (2005) Low crested coastal defence structures as artificial habitats for marine life: using ecological criteria in design. Coast Eng (in press)

Murray SN, Denis TG, Kido JS, Smith JR (1999) Human visitation and the frequency and potential effects of collecting on rocky intertidal populations in southern California marine reserves. CalCOFI Rep 40:100-106

Page HM, Dugan JE, Dugan DS, Richards JB, Hubbard DM (1999) Effects of an offshore oil platform on the distribution and abundance of commercially important crab species. Mar Ecol Prog Ser 185:47-57

Paine RT, Levin SA (1981) Intertidal landscapes: disturbance and the dynamics of patterns. Ecol Monogr 51:145-178

Rebele F (1994) Urban ecology and special features of urban ecosystems. Global Ecol Biogeogr 4:173-187

Southward AJ, Orton JH (1954) The effects of wave-action on the distribution and numbers of the commoner plants and animals living on the Plymouth breakwater. J Mar Biol Assoc UK 33:1-19

Underwood AJ (1997) Experiments in ecology: their logical design and interpretation using analysis of variance. Cambridge University Press, Cambridge

Submitted: November 19, 2004; Accepted: March 31, 2005

Proofs received from author(s): July 29, 2005 